Corneal and conjunctival drug permeability: Systematic comparison and pharmacokinetic impact in the eye

\title{
Ramsay, Eva
}

2018-07-01

Ramsay , E, del Amo, E M , Toropainen, E , Tengvall-Unadike , U , Ranta , V-P , Urtti , A \& Ruponen, M 2018 , ' Corneal and conjunctival drug permeability: Systematic comparison and pharmacokinetic impact in the eye ', European Journal of Pharmaceutical Sciences , vol. 119 , pp. 83-89 . https://doi.org/10.1016/j.ejps.2018.03.034

http://hdl.handle.net/10138/300635

https://doi.org/10.1016/j.ejps.2018.03.034

cc_by_nc_nd

acceptedVersion

Downloaded from Helda, University of Helsinki institutional repository.

This is an electronic reprint of the original article.

This reprint may differ from the original in pagination and typographic detail.

Please cite the original version. 


\title{
Accepted Manuscript
}

Corneal and conjunctival drug permeability: Systematic comparison and pharmacokinetic impact in the eye

Eva Ramsay, Eva M. del Amo, Elisa Toropainen, Unni TengvallUnadike, Veli-Pekka Ranta, Arto Urtti, Marika Ruponen

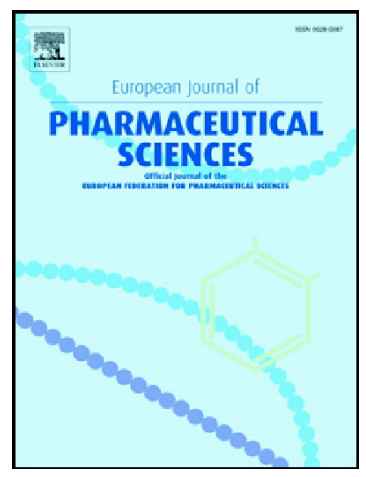

\author{
PII: $\quad$ S0928-0987(18)30155-6 \\ DOI: $\quad$ doi:10.1016/j.ejps.2018.03.034 \\ Reference: $\quad$ PHASCI 4463 \\ To appear in: $\quad$ European Journal of Pharmaceutical Sciences \\ Received date: $\quad 8$ January 2018 \\ Accepted date: $\quad 31$ March 2018
}

Please cite this article as: Eva Ramsay, Eva M. del Amo, Elisa Toropainen, Unni TengvallUnadike, Veli-Pekka Ranta, Arto Urtti, Marika Ruponen, Corneal and conjunctival drug permeability: Systematic comparison and pharmacokinetic impact in the eye. The address for the corresponding author was captured as affiliation for all authors. Please check if appropriate. Phasci(2017), doi:10.1016/j.ejps.2018.03.034

This is a PDF file of an unedited manuscript that has been accepted for publication. As a service to our customers we are providing this early version of the manuscript. The manuscript will undergo copyediting, typesetting, and review of the resulting proof before it is published in its final form. Please note that during the production process errors may be discovered which could affect the content, and all legal disclaimers that apply to the journal pertain. 


\title{
Corneal and conjunctival drug permeability: systematic comparison and pharmacokinetic impact in the eye
}

\author{
Eva Ramsay, a,,, Eva M. del Amo ${ }^{\mathrm{a}}$, Elisa Toropainen ${ }^{\mathrm{a}}$, Unni Tengvall-Unadikea, \\ Veli-Pekka Ranta ${ }^{a}$, Arto Urtti ${ }^{\mathrm{a}, \mathrm{b}}$, Marika Ruponen ${ }^{\mathrm{a}}$ \\ ${ }^{a}$ School of Pharmacy, Faculty of Health Sciences, University of Eastern Finland, 70211 Kuopio, \\ Finland \\ ${ }^{\mathrm{b}}$ Centre for Drug Research, Division of Pharmaceutical Biosciences, Faculty of Pharmacy, University \\ of Helsinki, P.O. Box 56, FI-00014 Helsinki, Finland \\ * Correspondence to: Eva Ramsay (Telephone: +358 29 4159636; Fax: +358 29 \\ 4159138). E-mail address: eva.ramsay@uef.fi (E. Ramsay).
}

\begin{abstract}
On the surface of the eye, both the cornea and conjunctiva are restricting ocular absorption of topically applied drugs, but barrier contributions of these two membranes have not been systemically compared. Herein, we studied permeability of 32 small molecular drug compounds across an isolated porcine cornea and built a quantitative structure-property relationship (QSPR) model for the permeability. Corneal drug permeability (data obtained for 25 drug molecules) showed a 52-fold range in permeability (0.09-4.70 x $10^{-6} \mathrm{~cm} / \mathrm{s}$ ) and the most important molecular descriptors in predicting the permeability were hydrogen bond donor, polar surface area and halogen ratio. Corneal permeability values were compared to their conjunctival drug permeability values. Ocular drug bioavailability and systemic absorption via conjunctiva were predicted for this drug set with pharmacokinetic simulations. Drug bioavailability in the aqueous humour was simulated to be less than $5 \%$ and trans-conjunctival systemic absorption was $34-79 \%$ of the dose. Loss of drug across the conjunctiva to the blood circulation restricts significantly ocular drug bioavailability and, therefore, ocular absorption does not increase proportionally with the increasing corneal drug permeability.
\end{abstract}

\section{Key-words}

Corneal permeability

Conjunctival permeability

Ocular drug delivery

Eye drops

Ocular absorption

Porcine

QSPR

\author{
Abbreviations \\ QSPR (quantitative structure-property relationship) \\ $\log \mathrm{D}_{7.4}$ (the logarithm of the octanol-water distribution coefficient at $\mathrm{pH} 7.4$ ) \\ $\mathrm{P}_{\text {app, CJ (conjunctival permeability) }}$ \\ $\mathrm{P}_{\text {app, Co (corneal permeability) }}$ \\ PSA (polar surface area) \\ HBD (hydrogen bond donor)
}


F (bioavailability)

$\mathrm{Cl}$ (clearance)

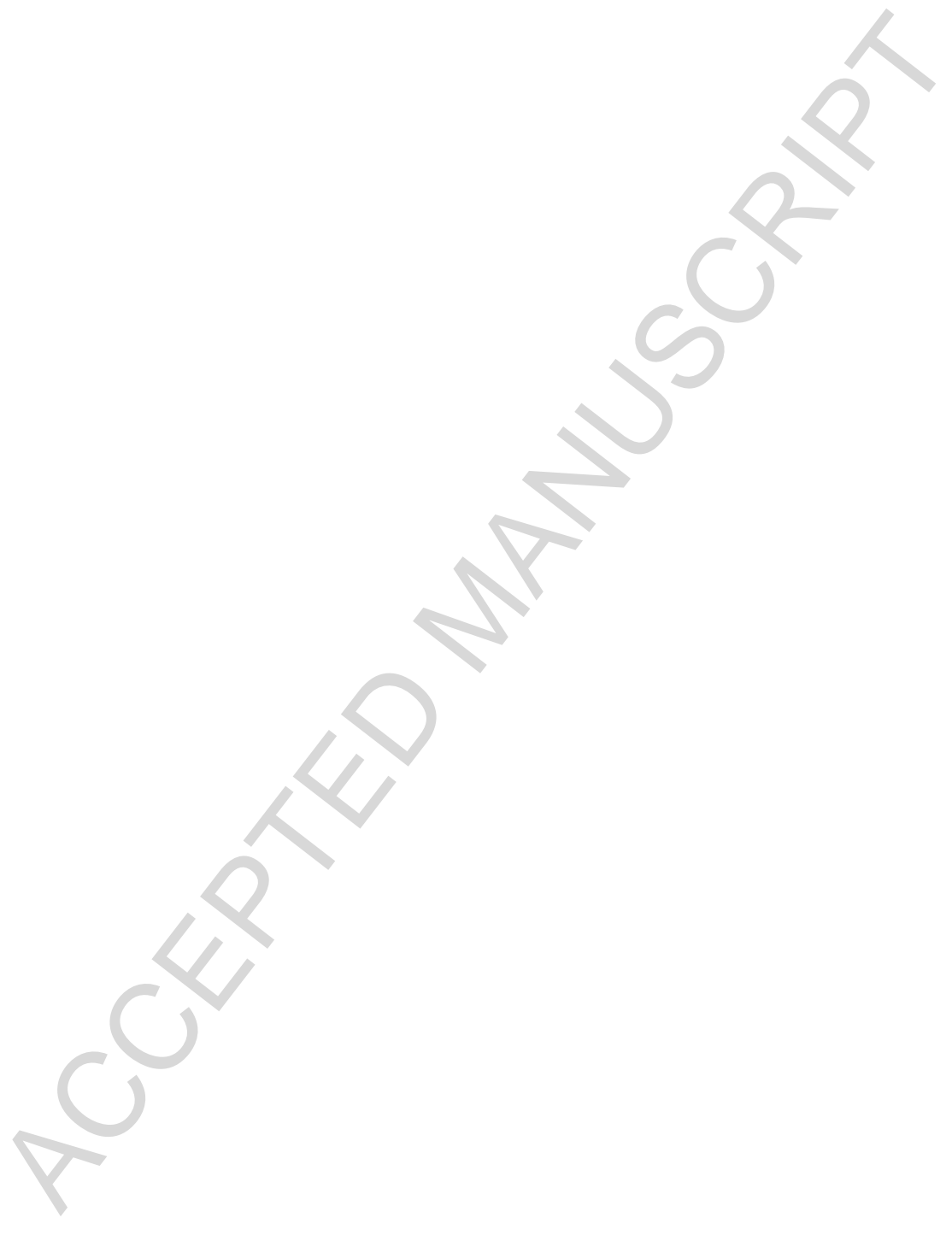




\section{Introduction}

Eye drops are the most commonly used drug formulation in ophthalmology (Urtti, 2006). They are widely used in the treatment of glaucoma, dry eye disease, infections and inflammatory conditions of the anterior part of the eye. Cornea and conjunctiva are the major tissue barriers that limit ocular drug absorption after instillation of eye drops. Cornea represents a tight barrier and route for drug absorption into the aqueous humour of the eye; the most commonly used sampling site in ocular bioavailability studies (Ahmed and Patton, 1987, 1985; Doane et al., 1978). Although, the conjunctival epithelium has intercellular tight junctions, it is leakier than the cornea (Ahmed and Patton, 1987; Huang et al., 1989; Hämäläinen et al., 1997) and has a surface area 17 times larger than cornea (Watsky et al., 1988). Conjunctiva is a route for ocular drug absorption, particularly to the iris and ciliary body (Ahmed and Patton, 1987, 1985; Shikamura et al., 2016), but most trans-conjunctival permeation leads to systemic drug absorption from the conjunctival sac (Urtti et al., 1994, 1985).

Cornea is composed of three main layers: the outermost epithelium, the middle stroma, and the innermost endothelium. The epithelium has tight junctions in the most superficial cells and it represents the ratelimiting barrier (Huang et al., 1989, 1983) that restricts drug permeation, especially for hydrophilic and large molecules (Ahmed et al., 1987; Huang et al., 1989). Hydrophilic and highly permeable stroma may limit permeation of very lipophilic drugs that show restricted partitioning from the epithelium to the stroma (Huang et al., 1983; Prausnitz and Noonan, 1998). The corneal endothelium is not considered to be a significant barrier in ocular drug absorption (Huang et al., 1983; Prausnitz and Noonan, 1998). The conjunctiva covers the inner side of the eyelids and the anterior part of the sclera thus serving as a barrier between lacrimal fluid and the eye (bulbar conjunctiva), as well as the blood circulation (palpebral conjunctiva). The conjunctiva is a semi-transparent mucous membrane, composed of multi-layered epithelium on top of vascularised connective tissue (Dartt, 2002).

After eye drop instillation, the drug is eliminated from the lacrimal fluid by drainage of extra solution, induced lacrimation, tear turnover, and conjunctival absorption (Lee and Robinson, 1979; Thombre and Himmelstein, 1984; Urtti et al., 1994, 1985). The pre-corneal loss factors and the corneal barrier limit ocular drug absorption, resulting in low bioavailability in the anterior chamber (typically less than 5\%) (Chrai and Robinson, 1974; Lazare and Horlington, 1975; Maurice and Mishima, 1984; Urtti et al., 1990). 
On the other hand, much larger fraction of the instilled dose will enter systemic blood circulation through conjunctiva and nasal mucosa (Chang and Lee, 1987; Urtti et al., 1994, 1985; Urtti and Salminen, 1993). For example, 70-80\% of timolol dose absorbs systemically (Chang and Lee, 1987; Urtti et al., 1985) and this caused systemic adverse drug effects (Nelson et al., 1986).

In order to develop new ocular drugs and drug formulations it is important to understand drug permeability at the cornea and conjunctiva, and their impact on ocular drug absorption. We published a study on permeability of 30 drugs in the isolated porcine conjunctivas and built a predictive quantitative structure-property relationship (QSPR) model for the permeability (Ramsay et al., 2017), but the field still lacks such predictive models for corneal drug permeability that are based on experimental data with a large set of drug compounds using similar test method. Ocular pharmacokinetic rabbit models have been published for topical eye drops (Deng et al., 2016; Grass and Lee, 1993; Himmelstein et al., 1978; Lee and Robinson, 1979; Makoid and Robinson, 1979; Miller et al., 1981; Thombre and Himmelstein, 1984), but these models are based on absorption of individual compounds and systematic comparisons of corneal and conjunctival drug permeability with wider chemical space and related pharmacokinetic models are missing. Such information would be useful in ocular drug development. We studied the corneal drug permeability across ex vivo porcine cornea and constructed a QSPR model for the corneal drug permeability. Additionally, the corneal and conjunctival (Ramsay et al., 2017) drug permeabilities were utilized to predict their impact on ocular and systemic drug absorption from the ocular surface.

\section{Materials and methods}

\subsection{Compounds and sample preparation}

We used 32 compounds that were in the cassette dose described earlier (Ramsay et al., 2017). The stock solutions were prepared, in either phosphate-buffer saline (PBS) or dimethyl sulfoxide (DMSO), at two different concentrations ( 1 and $10 \mathrm{mg} / \mathrm{mL}$ ), based on the analytical quantitation limits. The stock solutions of each drug were combined and diluted with BSS Plus (Alcon Laboratories, TX, USA). The final drug concentration in the apical side of the diffusion chamber was either 2 or $20 \mu \mathrm{g} / \mathrm{mL}$. The following ten drugs had a higher final concentration $(20 \mu \mathrm{g} / \mathrm{mL})$ : aztreonam, bromfenac, dexamethasone, diclofenac, indomethacin, levocabastine, methazolamide, prednisolone, quinidine, and tizanidine; whereas the rest of the cassette dose drugs had a lower final drug concentration $(2 \mu \mathrm{g} / \mathrm{mL})$. 


\subsection{Tissue preparation}

The porcine eyes were obtained from a local slaughterhouse and kept on ice in Dulbecco's phosphatebuffered saline (DPBS, pH 7.4) (Gibco, Invitrogen, NY, USA) during transport to the laboratory. The cornea was isolated and used in the permeability study. First, a small cut was made with the scalpel at the limbus, which separates the cornea from the conjunctiva. Then, the cornea was dissected from the eyeball by cutting along the limbus. During the preparation care was taken to avoid drying of the tissue, by applying on the cornea balanced salt solution, containing glutathione, glucose, bicarbonate, and electrolytes (BSS Plus, pH 7.4 and osmolarity 305 mOsm/kg) (Alcon Laboratories, TX, USA).

\subsection{Permeability study}

The isolated porcine cornea was first placed between two silicon rings (circular aperture of $0.64 \mathrm{~cm}^{2}$ ). Then the silicon-cornea-silicon set up was placed in a vertical Ussing/diffusion chamber (Harvard Apparatus, MA, USA). Both the apical and basolateral side of the diffusion chamber were filled with 5.5 $\mathrm{mL}$ or $6.5 \mathrm{~mL}$ pre-warmed BSS Plus buffer, respectively. The chambers were equipped with gas tubing providing the cornea with $5 \% \mathrm{CO}_{2}$ in $\mathrm{O}_{2}$, at a low speed. A circulating water bath (Haake DC10-W26/B, Thermo Scientific, MA, USA) was connected to a heat block surrounding the chambers and maintaining the temperature at $35^{\circ} \mathrm{C}$. The chambers were also equipped with electrode caps and glass barrel $\mathrm{Ag} / \mathrm{AgCl}$ electrodes (NaviCyte Electrodes, Harvard Apparatus, MA, USA), which were connected to a voltagecurrent clamp (VCC MC 6, Physiologic Instruments, CA, USA), for the measurement of trans-epithelial electrical resistance (TER). The permeability experiments were started by removing $550 \mu \mathrm{L}$ from the apical side and replacing with the same volume of the cassette dose. The initial donor concentration on the apical side (referring to the surface of the eye) was either 2 or $20 \mu \mathrm{g} / \mathrm{mL}$, depending on the drug. Samples of $500 \mu \mathrm{L}$ were then withdrawn from the basolateral side (referring to the aqueous humour side) at $15,30,45,60,75,90,120,150,180,210,240,270,300,330$ and $360 \mathrm{~min}$. The removed sample was replaced with the same volume of fresh BSS Plus buffer. At the beginning and at the end of the experiment a sample of $40 \mu \mathrm{L}$ was withdrawn from the apical side of the diffusion chamber for $\mathrm{P}_{\mathrm{app}}$ calculations. Samples were stored in $-20{ }^{\circ} \mathrm{C}$ until LC-MS/MS analysis.

The apparent permeability coefficient $\left(\mathrm{P}_{\mathrm{app}}\right)$ of the drug across the cornea was calculated as: $\mathrm{P}_{\text {app, }} \mathrm{CJ}$ $(\mathrm{cm} / \mathrm{s})=\mathrm{J} /\left(\mathrm{C}_{0} * \mathrm{~A}\right)$. Where $\mathrm{J}(\mathrm{ng} / \mathrm{s})$ is the drug flux (at the linear period after lag time) across the tissue, $\mathrm{C}_{0}$ 
is the initial donor concentration $\left(\mathrm{ng} / \mathrm{cm}^{3}\right)$, and $\mathrm{A}$ the area of the exposed tissue $\left(0.64 \mathrm{~cm}^{2}\right)$. The sink conditions were maintained during the permeability experiments, the drug concentration of the receiver site was $<10 \%$ of that on the donor site.

\subsection{Quantitative analysis}

The drug permeability was analysed with a LC-MS/MS system, which consisted of an Agilent 1290 series liquid chromatograph and an Agilent 6495 triple-quadrupole mass spectrometer (Agilent Technologies, Inc., USA) with electrospray ionization. For more detailed information please refer to Ramsay et al., 2017.

\subsection{Multivariate QSPR model generation}

A corneal drug permeability QSPR model was generated with multivariate analysis tools, composed of principal component analysis (PCA) and linear partial least square (PLS). For the model building, we used the apparent corneal permeability $\left(\mathrm{P}_{\mathrm{app}}, \mathrm{CO}\right)$ values of 25 small molecular drugs of the cassette dose and their 35 molecular descriptors.

\subsubsection{Molecular descriptors}

The 35 molecular descriptors were calculated based on the structure-data file format of 25 drugs of the cassette dose, using the ACDlabs® software (version 12, Advanced Chemistry Development, Inc., Toronto, Canada). The following molecular descriptors were generated: molecular weight (MW); $\mathrm{pK}_{\mathrm{a}}$ for the most acidic molecular form $\left(\mathrm{pK}_{\mathrm{a}} \mathrm{MA}\right) ; \mathrm{pK}_{\mathrm{a}}$ for the most basic molecular form ( $\left.\mathrm{pK}_{\mathrm{a}} \mathrm{MB}\right)$; $\mathrm{LogD}$ at pH 5.5, 7.4, and 10; LogP; polar surface area (PSA); freely rotatable bonds (FRB); hydrogen bond donors (HBD); hydrogen bond acceptors (HBA); HBtot (HBD + HBA); rule of 5 (Rule5); molar refractivity (MR); molar volume (MV); parachor; index of refraction (IR); surface tension (Ste); density; polarizability; $\mathrm{C}$ ratio; $\mathrm{N}$ ratio; $\mathrm{NO}$ ratio; hetero ratio; halogen ratio; number of rings (Num Rings); number of aromatic rings; 3-, 4-, 5- and 6-membered rings; and percentage of ionized form (acid, basic, neutral or zwitterion) at $\mathrm{pH} 7.4(\mathrm{Sol} \% \mathrm{~A}, \mathrm{~B}, \mathrm{~N}$ or Z (7.4)).

\subsubsection{Model Calibration and Building}

The QSPR model was calibrated and built using PCA and PLS, respectively (Simca ®, version 14.1, Umetrics AB, Umeå, Sweden). Descriptors that did not show normal distribution, where logarithmically 
transformed. The PCA was used to visualize the chemical space of the small molecular drugs. An external test set was chosen and excluded for later model validation. The drugs in the external data set were chosen randomly after drugs representing extreme descriptor and permeability values were ignored. During model calibration descriptors with narrow variance were excluded aiming for PCA model with a goodness of fit $\mathrm{R}^{2}$ and predictability $\mathrm{Q}^{2}$ higher than 0.5 . In the PLS, the relationship between the logarithm of the corneal permeability $\left(\log \mathrm{P}_{\mathrm{app}}, \mathrm{co}\right)$ and the remaining molecular descriptors of the drug set (training set) were modelled. Descriptors with a small influence on the model were excluded during the modelling based on the plots of PLS weight, coefficient, and variable importance for the projection.

\subsubsection{Model validation and applicability domain}

The reliability of the predictive PLS model was validated by internal and external validation. During the PLS model building the training set was internally validated by cross-validation $\left(Q^{2} Y\right)$, which meant that one-seventh of the data was left out for the cross-validation. The generated PLS model was externally validated by determining the regression coefficient, when plotting the predicted versus the experimental values of the external test set $\left(\mathrm{Q}_{\mathrm{e}}{ }^{2}\right)$. An accurate model shows values higher than 0.5 for $\mathrm{Q}^{2} \mathrm{Y}$ and $\mathrm{Q}_{\mathrm{e}}{ }^{2}$. Additionally, the Y-randomization test was conducted to prove the robustness of the model. The generated QSPR model can only be used for compounds, which have a similar chemical space as that of the training set drugs.

\subsection{Prediction of ocular and systemic drug absorption from the ocular surface}

The impact of corneal and conjunctival drug permeability on drug absorption to the aqueous humour and the systemic blood circulation were calculated based on corneal and conjunctival clearance $(\mathrm{Cl})$, as well as, tear flow rate (Q). However, we did not taking into account solution drainage and induced lacrimation that may take place after eye drop instillation (Chrai et al., 1973; Conrad et al., 1978). Corneal and conjunctival clearance values $(\mathrm{Cl}$ cornea, $\mathrm{Cl}$ conjunctiva $)$ were calculated by multiplying the apparent permeability in the cornea ( $\mathrm{P}_{\mathrm{app}, \mathrm{CO}}$; present study) or conjunctiva ( $\mathrm{P}_{\mathrm{app}, \mathrm{CJ}}$; Ramsay et al., 2017) for each drug with either the corneal surface area $\left(1.04 \mathrm{~cm}^{2}\right)$ or half of the conjunctival surface area $\left(8.83 \mathrm{~cm}^{2}\right)$, respectively. Half of the conjunctival surface area was used, because we assumed that the applied eye drop is quickly draining to the lower fornix where the drug is absorbed, rather than in the upper fornix. The human tear flow rate (Q tear) was reported in the literature as $1.2 \mu \mathrm{L} / \mathrm{min}$ (Lee and Robinson, 1986). Topical clearance from the lacrimal fluid was calculated as: 
Topical clearance $=C l_{\text {cornea }}+C l_{\text {conjunctiva }}+Q_{\text {tear }}$

Then, trans-corneal drug absorption was estimated as bioavailability $(\mathrm{F})$ in the aqueous humour as:

$$
F_{\text {aqueous humour }(\%)}=C l_{\text {cornea }} / \text { Topical clearance }
$$

Trans-conjunctival drug absorption to the systemic blood circulation was estimated as:

$$
F_{\text {conjunctival systemic }(\%)}=C l_{\text {conjunctiva }} / \text { Topical clearance }
$$

We assumed that the drug is evenly distributed in the tear fluid, and that the amount of drug that crosses the conjunctiva will enter the systemic circulation. Drug elimination from the ocular surface in the tear fluid may be partly absorbed to the systemic blood circulation, but this factor is very difficult to predict.

\section{Results}

\subsection{Corneal drug permeability}

Drug permeability in the isolated porcine corneas varied over 52-fold range $\left(0.09-4.70 \times 10^{-6} \mathrm{~cm} / \mathrm{s}\right)$ for 25 small molecular drugs (Table 1). Concentrations of seven drugs in the cassette dose (acyclovir, cephalexin, ciprofloxacin, dorzolamide, ganciclovir, lornoxicam, and methotrexate) were below the limit of quantification and the calculation of their $\mathrm{P}_{\text {app }}$ values was not possible. Integrity of the corneas were confirmed by the solute permeability values ( $\mathrm{P}_{\text {app, }} \mathrm{CO}$ ) and bioelectrical measurements (TER). The TER values were $372 \pm 54 \Omega \times \mathrm{cm}^{2}(\mathrm{n}=7)$ at the beginning and $917 \pm 362 \Omega \times \mathrm{cm}^{2}(\mathrm{n}=6)$ at the end of the permeability assays.

Table 1. Compounds in the permeability studies. MW, $\log \mathrm{D}_{7.4}, \mathrm{PSA}$ and HBD molecular descriptors, experimental $( \pm \mathrm{SD})$ and/ or predicted corneal permeability values, and the number (n) of isolated corneal tissue samples tested per drug. 


\begin{tabular}{|c|c|c|c|c|c|c|c|c|}
\hline Name & $M W$ & $\log D_{7.4}$ & $P S A^{a}$ & $H B D$ & $\begin{array}{c}\text { Halogen } \\
\text { ratio }^{b}\end{array}$ & $\begin{array}{l}\text { Experimental Papp, } \\
\text { Co } \\
\quad\left(10^{-7} \mathrm{~cm} / \mathrm{s}\right)\end{array}$ & $\begin{array}{l}\text { Predicted } \\
P_{\text {app }, \mathrm{CO}} \\
\quad\left(10^{-7} \mathrm{~cm} / \mathrm{s}\right) \\
\end{array}$ & $n$ \\
\hline Acetazolamide & 222.3 & -0.69 & 151.7 & 3 & 0.00 & $2.27 \pm 0.70$ & 1.74 & 3 \\
\hline Ampicillin * & 349.4 & -1.84 & 138.0 & 4 & 0.00 & $1.89 \pm 0.24$ & 1.37 & 3 \\
\hline Atenolol & 266.3 & -1.76 & 84.6 & 4 & 0.00 & $1.72 \pm 0.87$ & 2.00 & 7 \\
\hline Atropine & 289.4 & -1.09 & 49.8 & 1 & 0.00 & $5.64 \pm 2.15$ & 7.61 & 7 \\
\hline Aztreonam & 435.4 & -4.32 & 238.2 & 5 & 0.00 & $1.02 \pm 0.49$ & 0.66 & 3 \\
\hline Betaxolol & 307.4 & 0.43 & 50.7 & 2 & 0.00 & $15.80 \pm 10.70$ & 5.50 & 7 \\
\hline Brinzolamide & 383.5 & 4.19 & 163.8 & 3 & 0.00 & $1.36 \pm 0.35$ & 1.64 & 3 \\
\hline Bromfenac & 334.2 & -1.04 & 80.4 & 3 & 0.05 & $3.99 \pm 2.67$ & 4.01 & 5 \\
\hline Carteolol & 292.4 & -0.74 & 70.6 & 3 & 0.00 & $1.43 \pm 0.49$ & 3.13 & 7 \\
\hline $\begin{array}{l}\text { Dexamethasone } \\
*\end{array}$ & 392.5 & 2.03 & 94.8 & 3 & 0.04 & $1.57 \pm 0.75$ & 3.20 & 7 \\
\hline Diclofenac & 296.2 & 1.44 & 49.3 & 2 & 0.11 & $6.20 \pm 6.49$ & 12.03 & 5 \\
\hline Fluconazole * & 306.3 & 0.45 & 81.7 & 1 & 0.09 & $9.97 \pm 4.50$ & 9.76 & 7 \\
\hline Indomethacin & 357.8 & 0.98 & 68.5 & 1 & 0.04 & $5.03 \pm 3.62$ & 7.85 & 5 \\
\hline Ketorolac & 255.3 & -0.34 & 59.3 & 1 & 0.00 & $3.49 \pm 0.72$ & 6.65 & 4 \\
\hline Levocabastine & 420.5 & 1.55 & 64.3 & 1 & 0.03 & $4.08 \pm 2.16$ & 7.82 & 4 \\
\hline Lincomycin & 406.5 & -0.36 & 147.8 & 5 & 0.00 & $0.90 \pm 0.32$ & 0.96 & 7 \\
\hline Methazolamide & 236.3 & -0.21 & 138.9 & 2 & 0.00 & $4.74 \pm 1.66$ & 2.54 & 7 \\
\hline Nadolol & 309.4 & -1.54 & 82.0 & 4 & 0.00 & $1.22 \pm 0.41$ & 2.05 & 7 \\
\hline Pilocarpine & 208.3 & -0.39 & 44.1 & 0 & 0.00 & $17.86 \pm 6.02$ & 11.38 & 7 \\
\hline Pindolol * & 248.3 & -0.5 & 57.3 & 3 & 0.00 & $7.54 \pm 4.79$ & 3.68 & 4 \\
\hline Prednisolone & 360.4 & 1.63 & 94.8 & 3 & 0.00 & $2.03 \pm 0.89$ & 2.50 & 4 \\
\hline Propranolol & 259.3 & 0.79 & 41.5 & 2 & 0.00 & $15.18 \pm 14.66$ & 6.42 & 4 \\
\hline Quinidine * & 324.4 & 0.98 & 45.6 & 1 & 0.00 & $8.68 \pm 6.25$ & 8.14 & 7 \\
\hline Tizanidine & 253.7 & 2.04 & 90.4 & 2 & 0.06 & $47.04 \pm 17.57$ & & 4 \\
\hline Voriconazole & 349.3 & 1.21 & 76.7 & 1 & 0.12 & $31.68 \pm 15.34$ & 12.52 & 4 \\
\hline
\end{tabular}

${ }^{a}$ PSA is calculated based on topological PSA

${ }^{b}$ Halogen ratio, is calculated as the sum of all halogens $(F, C l, B r, I)$ divided by the sum of all heavy atoms (excluding hydrogen)

* external data set

\subsection{Multivariate QSPR model for corneal drug permeability}

The QSPR model was generated for 24 drugs excluding tizanidine that was an outlier and showed to bias the model in preliminary studies. The QSPR model generation stages and results are shown in Figure 1. 
A complete list of the 24 drugs and 35 molecular descriptors that were used for QSPR modelling are found in the Supplementary data A. The small molecular drug set represent a broad chemical space: MW of 208.3-435.4 Da, $\operatorname{LogD}_{7.4}$ from -4.3 to +4.2, PSA of 41.5-238.2 $\AA^{2}$, HBtot (HBA + HBD) of 4-18, and halogen ratio of $0-0.12$.

Before model calibration (PCA) an external test set of five drugs (ampicillin, dexamethasone, fluconazole, pindolol, and quinidine) was removed. In the present study, an internal test set of drugs was not used, due to the small set of drugs available. The PCA analysis was conducted with the remaining 19 drugs, and the following five descriptors were removed due to low variance: 3-, 4- and, 5-membered rings, number of rings, and percentage of ionized species. A statistically significant PCA model was obtained ( $\mathrm{R}^{2}$ of 0.87 and $\mathrm{Q}^{2}$ of $0.57,30$ descriptors) with four principal components explaining the variance of the descriptor space. The chemical space of the training set is illustrated with two principal components in Figure 2. The principal components explained $38 \% \mathrm{t}[1]$ and $22 \% \mathrm{t}[2]$ of the variance in the set, respectively.

\subsubsection{Model building (PLS), validation and applicability}

The training set of 19 drugs was used to generate a predictive model for corneal drug permeability. The final model showed that polar surface area (PSA), hydrogen bond donor (HBD) and halogen ratio were essential in permeability prediction (Table 2). The model showed acceptable statistical significance, with

goodness of fit $\mathrm{R}^{2} \mathrm{X}$ of 0.62 and $\mathrm{R}^{2} \mathrm{Y}$ of 0.69 , and goodness of prediction $\mathrm{Q}^{2} \mathrm{Y}$ of 0.63 . The regression coefficient of the predicted versus experimental corneal permeability for the external test set drugs $\left(\mathrm{Qe}^{2}\right)$ was 0.66 (Fig. 3). The model predicted the external test set with a mean fold error of 1.5. The robustness of the model, tested with Y-randomization test, was good (Supplementary data B). The model can be applied for predicting corneal drug permeability of new compounds with a similar chemical space as that of the training set drugs (Supplementary data A).

Table 2. The linear partial least square (PLS) model for the corneal drug permeability including validation results.

Model Descriptors $\quad R^{2} X^{a} \quad R^{2} Y^{a} \quad Q^{2} Y^{b} \quad Q e^{2 c} \quad Y-$




$$
\begin{array}{ccccccc}
\operatorname{LogP} \mathrm{Pap}_{\text {, co }}=-4.6823- & \text { PSA, HBD } & 0.62 & 0.69 & 0.63 & 0.66 & \text { Ok } \\
0.7670(\operatorname{logPSA}) \quad-0.1346(\mathrm{HBD})+ & \& & & & & & \\
\text { 3.0024(Halogen ratio) } & \begin{array}{c}
\text { Halogen } \\
\text { ratio }
\end{array} & & & & &
\end{array}
$$

${ }^{a} R^{2} X$ and $R^{2} Y$ describe the goodness of fit of the training set

${ }^{b} Q^{2} Y$ describe the goodness of prediction of the model

${ }^{c} Q e^{2}$ is the regression coefficient of predicted versus experimental values for the external test set

\subsection{Role of corneal and conjunctival permeability in ocular and systemic drug absorption from the ocular surface}

Based on the conjunctival drug permeability and simulations drug elimination from tear fluid across the conjunctiva had a great impact on bioavailability to the aqueous humour and trans-conjunctival systemic bioavailability. Based on the calculations, trans-conjunctival permeation of the test drugs is expected to lead to systemic absorption of 34-79\% of the drug dose. Only $0.3-4.4 \%$ of the applied dose reaches the aqueous humour via trans-corneal permeation (Fig. 4). Tear flow removes $18-66 \%$ of the dose to the nasal cavity and possibly further. It is noteworthy that the increase in the corneal drug permeability did not result in a proportional increase of ocular drug bioavailability, because the increased corneal permeability is associated with higher permeation in the conjunctiva that leads to drug loss to the systemic blood circulation. More than 50-fold increase in corneal drug permeability resulted in only 14-fold increase in drug absorption to the aqueous humour (Fig. 4). The clearance and bioavailability values of the 25 test compounds are available in the Supplementary data C.

\section{Discussion}

Small molecular drug compounds are widely used as eye drops to treat anterior segment diseases (Urtti, 2006). In this study we show that the drug permeability in isolated porcine cornea of the presented drug set varies over 52-fold range. Broad range of permeability values reflects the tight barrier in the corneal epithelium (Ahmed et al., 1987; Huang et al., 1989, 1983; Hämäläinen et al., 1997). For example, hydrophilic lincomycin $\left(0.90 \pm 0.32 \times 10^{-7} \mathrm{~cm} / \mathrm{s}\right)$ permeated much slower across the cornea than lipophilic voriconazole $\left(31.68 \pm 15.34 \times 10^{-7} \mathrm{~cm} / \mathrm{s}\right)$. Most of the permeability studies are done with rabbit cornea that seems to be more permeable than the porcine (Kidron et al., 2010; Loch et al., 2012; Prausnitz and Noonan, 1998; Wang et al., 1991). For instance pindolol has a 14 times smaller permeability in the porcine cornea compared to that of rabbit $\left(1.04 \pm 0.04 \times 10^{-5}\right.$, Wang et al., 1991). This is probably due to 
both thinner corneal epithelium and the whole cornea tissue of the rabbit compared to that of the porcine eye (Agarwal and Rupenthal, 2016). Relationship with the permeability in human cornea is difficult to assess because only very limited data is available from human cornea studies.

Corneal drug permeability is known to be affected by drug properties, such as lipophilicity, molecular size, and charge (Ahmed et al., 1987; Brechue and Maren, 1993; Chien et al., 1990; Huang et al., 1989, 1983; Liaw et al., 1992; Pescina et al., 2015; Schoenwald and Huang, 1983; Wang et al., 1991). Usually these studies have been performed with rabbit corneas and only a few compounds. Some reports include larger data sets on corneal drug permeability, but they have been collected from different sources with variable research methods (Kidron et al., 2010; Prausnitz and Noonan, 1998). In the present study, corneal permeability values were generated for 25 compounds using identical experimental set up. This should minimize variation that is related to the methods. Statistically valid QSPR model was generated based on the permeation data, and polar surface area (PSA), hydrogen bond donor (HBD), and halogen ratio adequately predict the corneal permeation. PSA and HBD have an inverse effect on drug permeability across the cornea, whereas the halogen ratio has a positive effect. PSA and the ability to form hydrogen bonds are important descriptors also in drug permeation across the porcine conjunctiva (Ramsay et al., 2017), rabbit cornea (Kidron et al., 2010), and human intestine (Linnankoski et al., 2006; Winiwarter et al., 1998).

Systematic quantitative comparison of porcine corneal and conjunctival permeation reveals that the cornea is $8.6 \pm 4.4$ times tighter barrier than the conjunctiva (Fig. 5). A similar pattern has been shown in studies with rabbit and bovine membranes (Ahmed et al., 1987; Huang et al., 1989; Hämäläinen et al., 1997; Loch et al., 2012; Wang et al., 1991). However, the range of permeability values was narrower in the conjunctiva ( 8.5 fold) than in the cornea (52 fold).

Pre-corneal flow (drainage, tear turnover) factors and permeability (cornea, conjunctiva) determine the overall ocular drug bioavailability. According to our simulations the trans-corneal drug bioavailability in the aqueous humour was less than $5 \%$ and, in many cases less than 1\% (Fig. 4). The simulations are in line with in vivo rabbit experiments showing low bioavailability to the aqueous humour (<5\%) (Chrai and Robinson, 1974; Lazare and Horlington, 1975; Maurice and Mishima, 1984; Urtti et al., 1990) and high systemic absorption after eye drop application (Chang and Lee, 1987; Urtti et al., 1994, 1985; Urtti 
and Salminen, 1993). It is important to note that the increase in ocular bioavailability is less than the proportional increase in the corneal permeability, because both ocular absorption and systemic loss are increased for compounds with high membrane permeability.

The simulations showed that a large fraction of the drug dose is eliminated to the systemic blood circulation across the conjunctiva (34-79\%). Large surface area of the relatively permeable conjunctiva explains this result that is in line with previous results with pilocarpine (Thombre and Himmelstein, 1984; Urtti et al., 1985). Also, intra-ocular absorption through bulbar conjunctiva is possible, but in this case the drug will distribute to the iris and ciliary body, not aqueous humour (Ahmed and Patton, 1987, 1985; Doane et al., 1978) and most of the drug results to the systemic circulation from sub-conjunctival space (Ranta et al., 2010). Thus, systemic absorption via conjunctiva is, in any case, 1-2 orders higher than ocular delivery to the aqueous humor. Large fraction of the dose enters the systemic circulation from the conjunctival fornix (Urtti et al., 1985), but in addition, part of the drug that flows to the nasal mucosa and further (such as the pharynx, mouth, and gastrointestinal tract) may be absorbed to the systemic circulation (Chang and Lee, 1987; Urtti and Salminen, 1993).

The rate of solution drainage from the ocular surface is difficult to assess and it depends on many factors, such as instilled volume, viscosity and induced lacrimation (Chrai et al., 1973; Conrad et al., 1978). Drainage may shorten the contact time of the drug with the cornea and conjunctiva decreasing the ocular bioavailability even further. However, it should not affect the ratio of corneal and conjunctival drug absorption (Fig. 4). Also, in the case of controlled release systems that reside in the conjunctival fornix, the drainage factor is less relevant and numbers in Figure 4 may be directly applicable. For eye drops, Figure 4 shows the maximal ocular bioavailability values that can be attained.

A broad range of studies has been conducted in order to improve ocular drug bioavailability. The main strategies have been to increase corneal drug permeability and to increase drug retention time at the surface of the eye (Chang et al., 1988; Chang and Lee, 1987; Kaur et al., 2004; Urtti et al., 1990, 1985; Zhang et al., 2004). Corneal drug permeability is expected to improve ocular trans-corneal bioavailability, but the effect is less than one would predict. For new compounds, corneal and conjunctival permeability values can be estimated using the QSPR models from this study and Ramsay et al. (2017). These values, can be conveniently used to estimate the maximal ocular bioavailability that 
can be attained and potential impact of solution drainage. Thus, this study provides new generalizable data and models to augment biopharmaceutical development of new topical ocular medications.

In conclusion, we studied corneal permeability of a compound set with wide chemical space and generated a valid QSPR model for prediction of the corneal drug permeation. Follow-up kinetic simulations encompassed permeability and flow factors, and provided generalized view on ocular drug bioavailability thereby providing tools for ocular drug development.

\section{Acknowledgements}

We would like to thank Dr Heidi Kidron for her valuable advice in the QSPR model generation. Lea Pirskanen is acknowledged for her skillful technical assistance. This study was supported by Leo, Mary, and Mary-Ann Hackman Foundation, the Alexander project (EU-FP7; 280761), and Academy of Finland.

\section{References}

Agarwal, P., Rupenthal, I.D., 2016. In vitro and ex vivo corneal penetration and absorption models. Drug Deliv. Transl. Res. 634-647. https://doi.org/10.1007/s13346-015-0275-6

Ahmed, I., Gokhale, R.D., Shah, M. V., Patton, T.F., 1987. Physicochemical determinants of drug diffusion across the conjunctiva, sclera, and cornea. J. Pharm. Sci. 76, 583-586.

Ahmed, I., Patton, T.F., 1987. Disposition of timolol and inulin in the rabbit eye following corneal versus non-corneal absorption. Int. J. Pharm. 38, 9-21.

Ahmed, I., Patton, T.F., 1985. Importance of the Noncorneol Absorption Route in Topicol Ophthalmic Drug Delivery. Invest. Ophthalmol. Vis. Sci. 26, 584-587.

Brechue, W.F., Maren, T.H., 1993. pH and drug ionization affects ocular pressure lowering of topical carbonic anhydrase inhibitors. Investig. Ophthalmol. Vis. Sci. 34, 2581-2587.

Chang, S.C., Chien, D.S., Bundgaard, H., Lee, V.H.L., 1988. Relative effectiveness of prodrug and viscous solution approaches in maximizing the ratio of ocular to systemic absorption of topically applied timolol. Exp. Eye Res. 46, 59-69. https://doi.org/10.1016/S0014-4835(88)80093-9

Chang, S.C., Lee, V.H., 1987. Nasal and conjunctival contributions to the systemic absorption of topical timolol in the pigmented rabbit: implications in the design of strategies to maximize the ratio of ocular to systemic absorption. J Ocul Pharmacol 3, 159-169.

Chien, D.-S., Homsy, J.J., Gluchowskil, C., Tang-liu, D.D., 1990. Corneal and conjunctival/scleral penetration of p-aminoclonidine, AGN 190342, and clonidine in rabbit eyes. Curr. Eye Res. 9, 1051-1059.

Chrai, S.S., Patton, T.F., Mehta, A., Robinson, J.R., 1973. Lacrimal and instilled fluid dynamics in rabbit eyes. J. Pharm. Sci. 62, 1112-1121. https://doi.org/10.1002/jps.2600620712

Chrai, S.S., Robinson, J.R., 1974. Corneal permeation of topical pilocarpine nitrate in the rabbit. Am. J. Ophthalmol. 77, 735-739.

Conrad, J.M., Reay, W.A., Polcyn, R.E., Robinson, J.R., 1978. Influence of Tonicity and pH on Lacrimation and Ocular Drug Bioavailability. J. Parenter. Drug Assoc. 32, 149-161. 
Dartt, D.A., 2002. Regulation of mucin and fluid secretion by conjunctival epithelial cells. Prog. Retin. Eye Res. 21, 555-576.

Deng, F., Ranta, V.P., Kidron, H., Urtti, A., 2016. General Pharmacokinetic Model for Topically Administered Ocular Drug Dosage Forms. Pharm. Res. 33, 2680-2690. https://doi.org/10.1007/s11095-016-1993-2

Doane, M.G., Jensen, A.D., Dohlman, C.H., 1978. Penetration routes of topically applied eye medications. Am. J. Ophthalmol. 85, 383-386.

Grass, G.M., Lee, V.H.L., 1993. A model to predict aqueous humor and plasma pharmacokinetics of ocularly applied drugs. Investig. Ophthalmol. Vis. Sci. 34, 2251-2259.

Himmelstein, K.J., Guvenir, I., Patton, T.F., 1978. Preliminary pharmacokinetic model of pilocarpine uptake and distribution in the eye. J. Pharm. Sci. 67, 603-606. https://doi.org/10.1002/jps.2600670507

Huang, A.J.W., Tseng, S.C.G., Kenyon, K.R., 1989. Paracellular permeability of corneal and conjunctival epithelia. Investig. Ophthalmol. Vis. Sci. 30, 684-689.

Huang, H.-S., Schoenwald, R.D., Lach, J.L., 1983. Corneal Penetration Behavior of $\beta$-Blocking Agents II: Assessment of Barrier Contributions. J. Pharm. Sci. 72, 1272-1278.

Hämäläinen, K.M., Kananen, K., Auriola, S., Kontturi, K., Urtti, 1997. Characterization of Paracellular and Aqueous Penetration Routes in Cornea , Conjunctiva, and Sclera 38, 627-634.

Kaur, I.P., Garg, A., Singla, A.K., Aggarwal, D., 2004. Vesicular systems in ocular drug delivery: An overview. Int. J. Pharm. https://doi.org/10.1016/j.ijpharm.2003.09.016

Kidron, H., Vellonen, K.S., del Amo, E.M., Tissari, A., Urtti, A., 2010. Prediction of the corneal permeability of drug-like compounds. Pharm. Res. 27, 1398-1407.

Lazare, R., Horlington, M., 1975. Pilocarpine levels in the eyes of rabbits following topical application. Exp. Eye Res. 21, 281-287.

Lee, V.H.-L., Robinson, J.R., 1979. Mechanistic and quantitative evaluation of precorneal pilocarpine disposition in albino rabbits. J. Pharm. Sci. 68, 673-684.

Lee, V.H.L., Robinson, J.R., 1986. Review : Topical Ocular Drug Delivery : Recent Developments and Future Challenges. Ocul. Pharmacol. 2, 67-108.

Liaw, J., Rojanasakul, Y., Robinson, J.R., 1992. The effect of drug charge type and charge density on corneal transport. Int. J. Pharm. 88, 111-124. https://doi.org/10.1016/0378-5173(92)90308-O

Linnankoski, J., Mäkelä, J.M., Ranta, V.-P., Urtti, A., Yliperttula, M., 2006. Computational prediction of oral drug absorption based on absorption rate constants in humans. J. Med. Chem. 49, 3674-81.

Loch, C., Zakelj, S., Kristl, A., Nagel, S., Guthoff, R., Weitschies, W., Seidlitz, A., 2012. Determination of permeability coefficients of ophthalmic drugs through different layers of porcine, rabbit and bovine eyes. Eur. J. Pharm. Sci. 47, 131-138.

Makoid, M.C., Robinson, J.R., 1979. Pharmacokinetics of topically applied pilocarpine in the albino rabbit eye. J. Pharm. Sci. 68, 435-443. https://doi.org/10.1002/jps.2600680411

Maurice, D.M., Mishima, S., 1984. Ocular Pharmacokinetics, in: Sears, M.L. (Ed.), Handbook of Experimental Pharmacology/ Pharmacology of the Eye. Springer-Verlag, Berlin-Heidelberg, pp. 19-116.

Miller, S.C., Himmelstein, K.J., Patton, T.F., 1981. A physiologically based pharmacokinetic model for the intraocular distribution of pilocarpine in rabbits. J. Pharmacokinet. Biopharm. 9, 653-77. https://doi.org/10.1007/BF01070899

Nelson, W.L., Fraunfelder, F.T., Sills, J.M., B., A.J., Kuritsky, J.N., 1986. Adverse respiratory and cardiovascular events atributed to timolol opthalmic solution, 1978-1985. Am. J. Ophthalmol. 102, 606-611.

Pescina, S., Govoni, P., Potenza, A., Padula, C., Santi, P., Nicoli, S., 2015. Development of a convenient 
ex vivo model for the study of the transcorneal permeation of drugs: Histological and permeability evaluation. J. Pharm. Sci. 104, 63-71. https://doi.org/10.1002/jps.24231

Prausnitz, M.R., Noonan, J.S., 1998. Permeability of Cornea, Sclera, and Conjunctiva: A Literature Analysis for Drug Delivery to the Eye. J. Pharm. Sci. 87, 1479-1488.

Ramsay, E., Ruponen, M., Picardat, T., Tengvall, U., Tuomainen, M., Auriola, S., Toropainen, E., Urtti, A., del Amo, E.M., 2017. Impact of Chemical Structure on Conjunctival Drug Permeability: Adopting Porcine Conjunctiva and Cassette Dosing for Construction of In Silico Model. J. Pharm. Sci. 106, 2463-2471. https://doi.org/10.1016/j.xphs.2017.04.061

Ranta, V.-P., Mannermaa, E., Lummepuro, K., Subrizi, A., Laukkanen, A., Antopolsky, M., Murtomäki, L., Hornof, M., Urtti, A., 2010. Barrier analysis of periocular drug delivery to the posterior segment. J. Control. Release 148, 42-48.

Schoenwald, R.D., Huang, H.-S., 1983. Corneal Penetration Behavior of $\beta$-Blocking Agents I: Physicochemical Factors. J. Pharm. Sci. 72, 1266-1272. https://doi.org/10.1002/jps.2600721108

Shikamura, Y., Yamazaki, Y., Matsunaga, T., Sato, T., Ohtori, A., Tojo, K., 2016. Hydrogel Ring for Topical Drug Delivery to the Ocular Posterior Segment. Curr. Eye Res. 41, 653-661.

Thombre, A.G., Himmelstein, K.J., 1984. Quantitative Evaluation of Topically Applied Pilocarpine in the Precorneal Area. J. Pharm. Sci. 73, 219-222.

Urtti, A., 2006. Challenges and obstacles of ocular pharmacokinetics and drug delivery. Adv. Drug Deliv. Rev. 58, 1131-1135.

Urtti, A., Pipkin, J.D., Rork, G., Sendo, T., Finne, U., Repta, A.J., 1990. Controlled drug delivery devices for experimental ocular studies with timolol 2. Ocular and systemic absorption in rabbits. Int. J. Pharm. 61, 241-249.

Urtti, A., Rouhiainen, H., Kaila, T., Saano, V., 1994. Controlled Ocular Timolol Delivery: Systemic Absorption and Intraocular Pressure Effects in Humans. Pharm. Res. An Off. J. Am. Assoc. Pharm. Sci.

Urtti, A., Salminen, L., 1993. Minimizing Systemic Absorption of Topically Administered Ophthalmic Drugs. Surv. Ophthalmol. 37, 425-456.

Urtti, A., Salminen, L., Miinalainen, O., 1985. Systemic absorption of ocular pilocarpine is modified by polymer matrices. Int. J. Pharm. 23, 147-161.

Wang, W., Sasaki, H., Chien, D.-S., Lee, V.H.L., 1991. Lipophilicity influence on conjunctival drug penetration in the pigmented rabbit: A comparison with corneal penetration. Curr. Eye Res. 10, 571579.

Watsky, M.A., Jablonski, M.M., Edelhauser, H.F., 1988. Comparison of conjunctival and corneal surface areas in rabbit and human. Curr. Eye Res. 7, 483-486.

Winiwarter, S., Bonham, N.M., Ax, F., Hallberg, A., Lennernäs, H., Karlén, A., 1998. Correlation of human jejunal permeability (in vivo) of drugs with experimentally and theoretically derived parameters. A multivariate data analysis approach. J. Med. Chem. 41, 4939-4949.

Zhang, W., Prausnitz, M.R., Edwards, A., 2004. Model of transient drug diffusion across cornea. J. Control. Release 99, 241-258. https://doi.org/10.1016/j.jconrel.2004.07.001 


\section{Figure captions}

Figure 1. A schematic diagram of the different steps of QSPR model generation for corneal drug permeability prediction.

Figure 2. The PCA score plot of the training set (19 compounds) representing the chemical space, which was based on 30 different molecular descriptors.

Figure 3. The predicted versus the experimental corneal drug permeability of the external test set drugs. The dotted lines represent a 3-fold error line.

Figure 4. Aqueous humour drug bioavailability $(\mathrm{F})$ versus corneal drug permeability $\left(\mathrm{P}_{\mathrm{app}}, \mathrm{CO}\right)$ for the 25 drugs of the cassette dose.

Figure 5. Conjunctival permeability ( $\left.\mathrm{P}_{\text {app }, C J}\right)$ (Ramsay et al., 2017) versus corneal permeability $\left(\mathrm{P}_{\text {app, }} \mathrm{CO}\right)$ (from Table 1) for 25 drugs. Dotted lines represent: same permeability (1:1) or 9 times larger conjunctival than corneal permeability $(9: 1)$. 


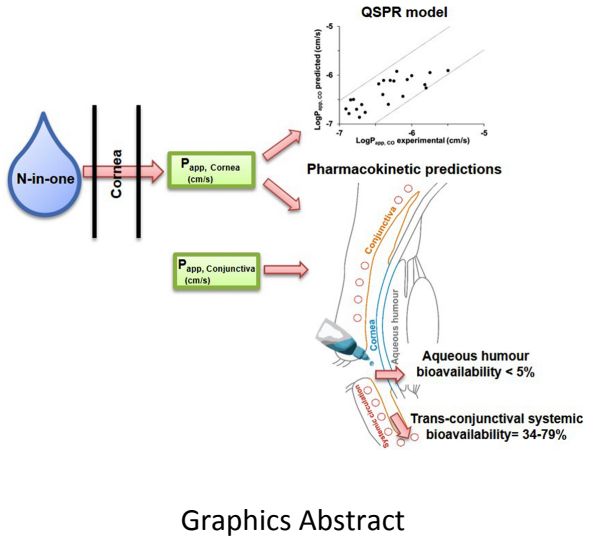




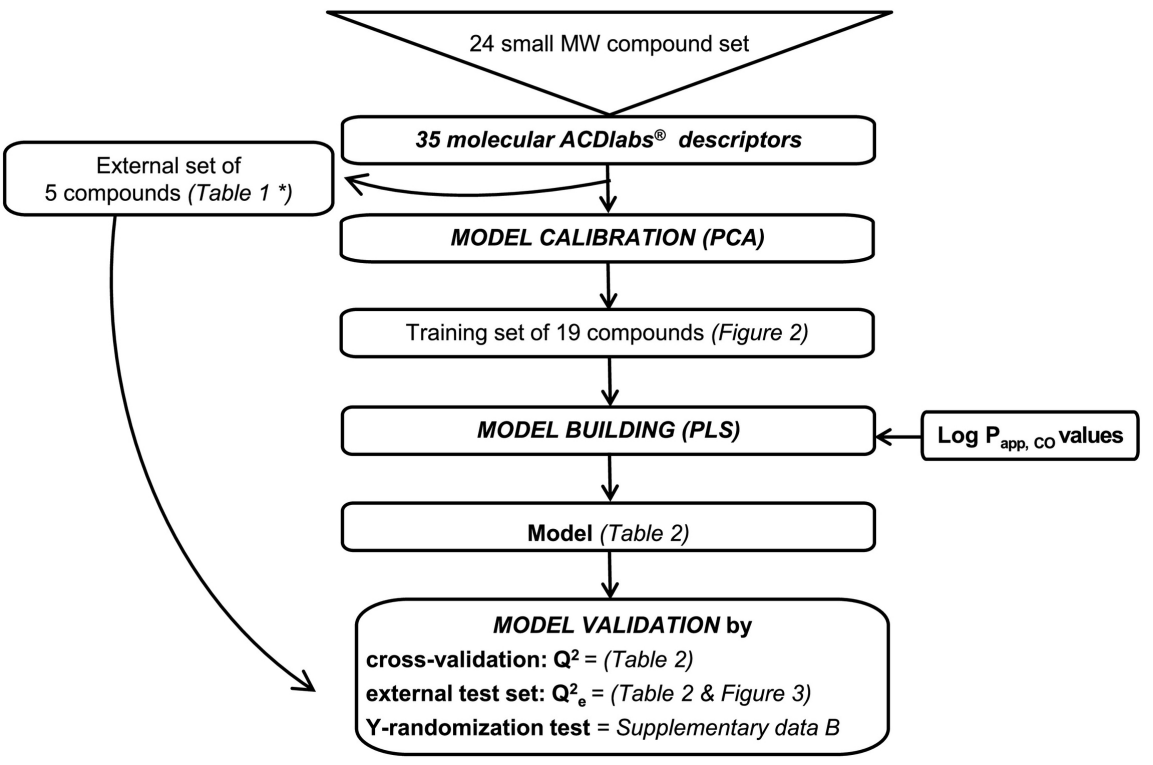

Figure 1 


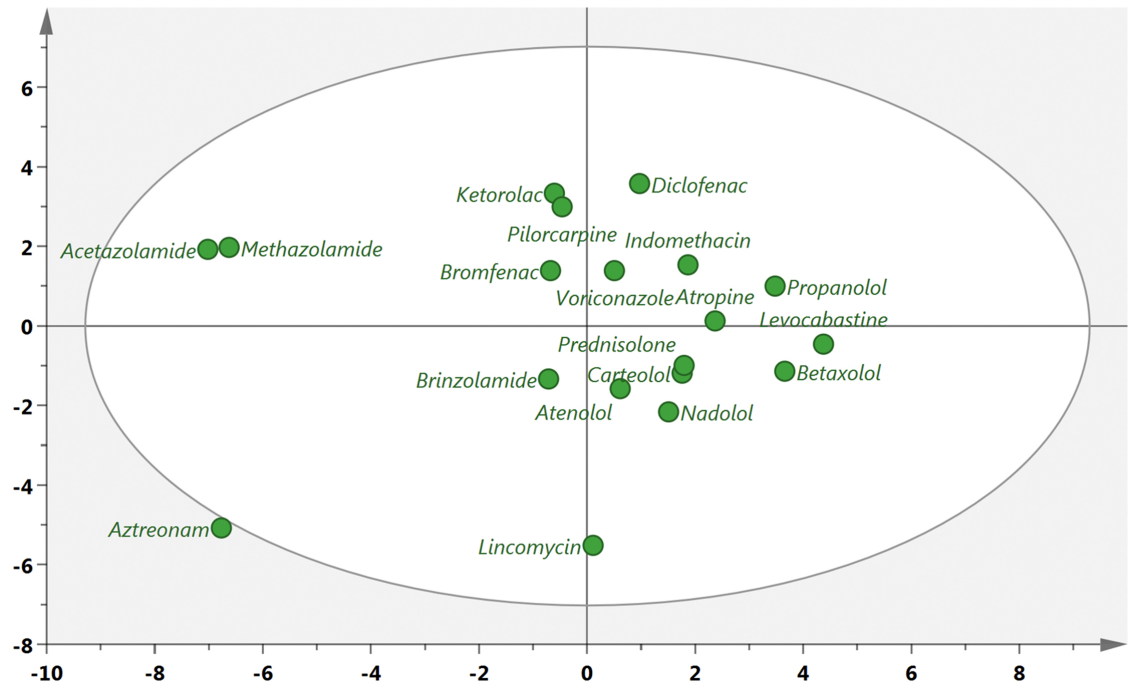

Figure 2 


\section{External test set \\ $R^{2}=0.66$}

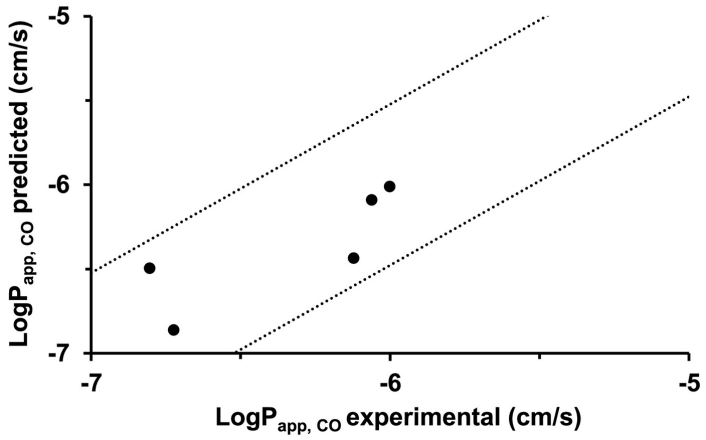

Figure 3 


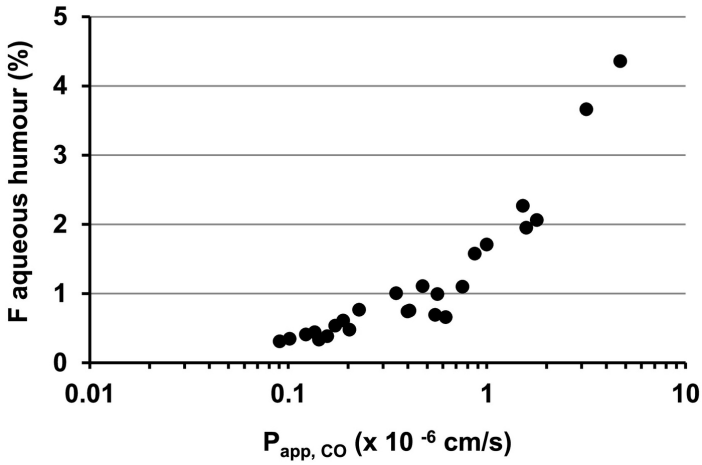

Figure 4 


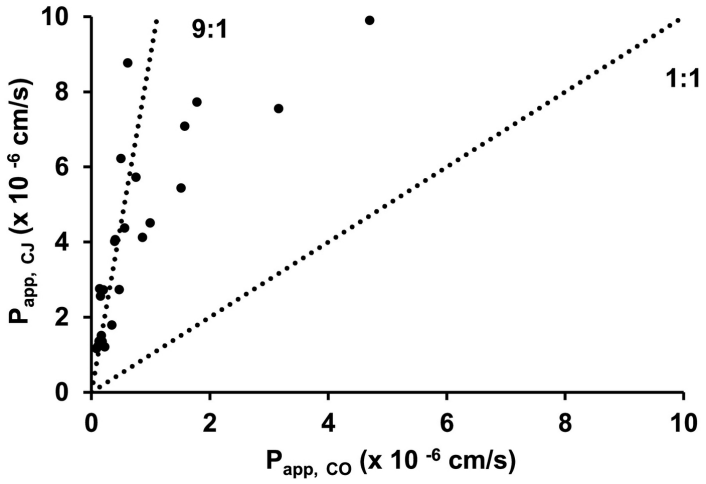

Figure 5 